\title{
Easy detection of chromatin binding proteins by the histone association assay
}

\author{
Robin M. Ricke ${ }^{1}$ and Anja-Katrin Bielinsky ${ }^{1 *}$ \\ 1Department of Biochemistry, Molecular Biology and Biophysics, University of Minnesota, Minneapolis, MN 55455.

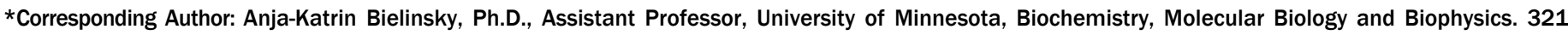 \\ Church Street SE, 6-155 Jackson Hall, Minneapolis, MN 55455. Phone: 612-624-2469; Fax: 612-625-2163; Email: bielinsk@cbs.umn.edu
}

Submitted: March 22, 2005; Revised: April 8, 2005; Accepted: April 14, 2005.

Indexing terms: Chromatin; Cross-linking Reagents; Formaldehyde; Histones; Immunoprecipitation.

Abbreviations: ChIP, Chromatin Immunoprecipitation; HAA, Histone Association Assay; McM10, Minichromosome Maintenance Protein 10; Orc2, Origin Recognition Complex protein 2; WCE, Whole Cell Extract.

\section{ABSTRACT}

The Histone Association Assay provides an easy approach for detecting proteins that bind chromatin in vivo. This technique is based on a chromatin immunoprecipitation protocol using histone H3-specific antibodies to precipitate bulk chromatin from crosslinked whole cell extracts. Proteins that co-precipitate with chromatin are subsequently detected by conventional SDS-PAGE and Western blot analysis. Unlike techniques that separate chromatin and nonchromatin interacting proteins by centrifugation, this method can be used to delineate whether a protein is chromatin associated regardless of its innate solubility. Moreover, the relative amount of protein bound to DNA can be ascertained under quantitative conditions. Therefore, this technique may be utilized for analyzing the chromatin association of proteins involved in diverse cellular processes.

\section{INTRODUCTION}

The association of cellular proteins with chromatin can elicit diverse responses from the cell including transcriptional activation or repression, initiation or inhibition of DNA replication, or chromatin remodeling to name a few examples. Therefore, the ability to detect the binding of protein factors to chromatin has an immense impact on our understanding of very basic and essential cellular processes. In the past decade, chromatin immunoprecipitation (ChIP) has become a widely utilized approach to monitor the association of proteins with specific DNA sequences. ChIP relies on the fact that formaldehyde treatment creates chemical crosslinks between proteins and DNA. Following crosslinking, the resulting chromatin is sheared and the protein of interest is immunoprecipitated. Co-precipitating DNA is typically detected using Southern hybridization (1) or
PCR $(2,3)$. True sites of the DNA:protein interaction are confirmed by comparison of the relative enrichment of specific sequences compared to physiologically irrelevant control regions. How ubiquitous this technique has become is further evidenced by the development of numerous variations. For example, the ChIP protocol has been modified for the cloning and subsequent identification of transcription factor binding sites $(4,5)$ and for mapping binding sites of a particular protein on a genome wide scale in combination with microarray analysis (6-10). Moreover, ChIP has been used to determine the temporal regulation underlying the sequential occupation of the same stretch of DNA by multiple proteins $(11,12)$. Intriguingly, because formaldehyde efficiently produces protein:nucleic acid as well as protein:protein crosslinks (13), this method can, in principle, be utilized to detect proteins that bind DNA directly as well as those that bind DNA through other 
factors. There are, however, some isolated incidences where formaldehyde crosslinks were insufficient to examine the association of a DNA-binding protein with chromatin (14). Despite the many current modifications of ChIP, until recently, the technique has not been adapted for examining the association of proteins with bulk chromatin.

In order to analyze the association of a particular protein with bulk chromatin, typically crude chromatin fractionation techniques are performed (15-18). The separation of chromatin and non-chromatin associated proteins is achieved by subjecting whole cell extract (WCE) to centrifugal forces of approximately $15,000 \mathrm{x} \mathrm{g}$. Because of their high molecular weight, long chromatin fibers migrate with the pellet. To confirm that a candidate protein is truly chromatin associated and not associated with the pellet due to its insolubility, the pellet or WCE can be treated enzymatically with either deoxyribonuclease (DNase) or micrococcal nuclease (MNase) to degrade DNA or release nucleosomes, respectively $(15,16,18)$. Proteins that are inherently insoluble will not be released following enzymatic treatment and therefore cannot be distinguished as chromatin bound using this approach. A modification of this approach precludes insoluble proteins from cofractionating with chromatin by using limited MNase digestion to release polynucleosomes $(19,20)$. However, during this procedure usually some material is lost, making a quantitative assessment of the relative amount of protein that is chromatin bound unfeasible. In order to quantitatively analyze the chromatin binding of proteins including those that are insoluble in WCE, we developed a new assay, the histone association assay (HAA), that permits detection of chromatin associated proteins regardless of their innate solubility (21).

The HAA is a variation of ChIP. Chromatin associated proteins are analyzed based on their ability to coprecipitate with histones in formaldehyde crosslinked cell extracts (Fig. 1). Specifically, cells are first crosslinked with formaldehyde to capture the binding of proteins to chromatin. In order to keep the chromatin in the soluble fraction, the chromatin is sheared into smaller fragments using sonication. Subsequently, bulk chromatin is immunoprecipitated with histone H3-specific antibodies.
Because formaldehyde crosslinks are readily reversible with heat, the co-precipitating proteins can then be detected using conventional SDS-PAGE and Western blot analysis. Importantly, because chromatin associated proteins immunoprecipitate with core histones when cells are treated with a chemical crosslinker, a protein's intrinsic solubility will not affect whether it can be detected by this method. Moreover, the crosslinked extracts appear to be more resistant to proteases than untreated extracts and lastly, relatively transient protein interactions can be captured as well. The main advantage of the HAA is that it allows for the quantitative assessment of the relative amount of cellular protein that is bound to chromatin (21). Therefore, this approach can be used to analyze many diverse chromatin associated proteins.

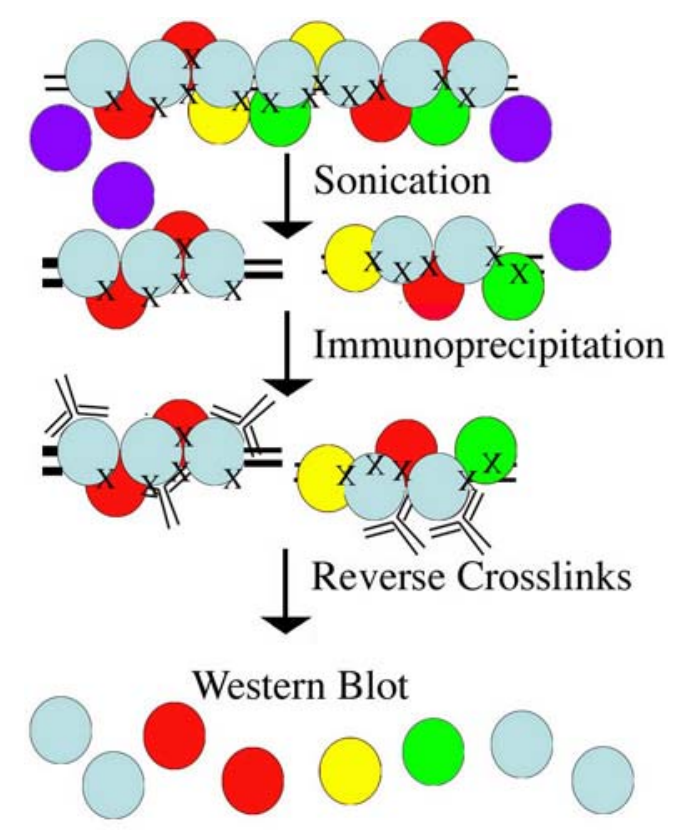

Fig. 1: Schematic of the histone association assay. The histone association assay is an adaptation of chromatin immunoprecipitation. Chromatin bound proteins (red, yellow, and green circles) are detected independent of non-chromatin bound proteins (purple circles) based on their ability to co-precipitate with histones (core histones shown as light blue circles) in formaldehyde crosslinked (black X) cell extracts.

Here, we provide an in-depth technical review of the HAA using the insoluble DNA-binding protein minichromosome maintenance protein 10 (Mcm10) of $S$. cerevisiae as an example. In particular, we focus on the following three aspects: 1) formaldehyde cross-linking efficiency, 2) controls for non-specific histone association and 3) conditions for quantitative binding assays. 


\section{MATERIALS AND METHODS}

\section{Qualitative histone association assay}

Cells were treated with formaldehyde at a final concentration of $1 \%$ for 15 minutes. The reaction was quenched with the addition of glycine to a final concentration of $125 \mathrm{mM}$. Then the cell pellet was washed twice in 1 volume TBS (20 mM Tris-Cl pH 7.4, $150 \mathrm{mM} \mathrm{NaCl}$ ) and resuspended in $400 \mu \mathrm{l}$ ice-cold ChIP lysis buffer (50 mM HEPES-KOH pH 7.5, $140 \mathrm{mM} \mathrm{NaCl}$, $1 \mathrm{mM}$ EDTA, 1\% Triton X100, 0.1\% sodium deoxycholate and protease inhibitors). Acid-washed glass beads were added to half the volume and the sample was vortexed for 40 minutes at $4^{\circ} \mathrm{C}$. The resulting WCE was separated from the glass beads. To fragment the chromatin into pieces ranging from $500 \mathrm{bp}$ to $2 \mathrm{~kb}$, the whole cell extract was sonicated three times for 10 seconds, ensuring that the sample was on ice for at least one minute between sonications. The WCE was then centrifuged for 5 minutes at $20,000 \times \mathrm{g}$ at $4^{\circ} \mathrm{C}$. The supernatant was retained and centrifuged for 15 minutes at $20,000 \times \mathrm{g}$ at $4^{\circ} \mathrm{C}$. For the histone $\mathrm{H} 3$ immunoprecipitations, $100 \mu \mathrm{l}$ extract (which corresponds to approximately $1 \mathrm{mg}$ total protein, as measured by the Bradford assay) was added to $100 \mu \mathrm{l}$ ice-cold ChIP lysis buffer and $3 \mu \mathrm{g}$ rabbit polyclonal histone H3 antibody (Abcam \#ab1791). Samples were incubated overnight at $4^{\circ} \mathrm{C}$ with shaking and in the morning, $20 \mu \mathrm{g}$ single-stranded herring sperm DNA and $50 \mu \mathrm{l}$ of a $50 \%$ protein G Sepharose beads solution (w/v) in ChIP lysis buffer (Amersham) were added. The sample was incubated at $4^{\circ} \mathrm{C}$ with shaking for 90 minutes. The beads were washed twice with $1 \mathrm{ml} \mathrm{ChIP}$ lysis buffer, once in $1 \mathrm{ml} \mathrm{ChIP} \mathrm{lysis} \mathrm{buffer} \mathrm{containing} 500$ $\mathrm{mM} \mathrm{NaCl}$ and then once in $1 \mathrm{ml}$ ChIP washing buffer (10 $\mathrm{mM}$ Tris- $\mathrm{Cl} \mathrm{pH}$ 8.0, $0.25 \mathrm{M} \mathrm{LiCl}, 0.5 \% \mathrm{NP} 40$ and $0.5 \%$ sodium deoxycholate). Finally, the beads were washed once more in $1 \mathrm{ml}$ ChIP lysis buffer and resuspended in $50 \mu \mathrm{l} 2$ X Laemmli loading buffer (4\% SDS, 20\% glycerol, $120 \mathrm{mM}$ Tris-Cl pH 6.8, 200 mM DTT, 0.1\% bromophenol blue). To reverse the crosslinks, the inputs and histone H3 immunoprecipitates were boiled for at least 30 minutes. Chromatin associated proteins were detected by Western blot. Histone H2B (Upstate) was detected as a control.

\section{Quantitative histone association assay}

Cells were crosslinked and extract was prepared as described. To precipitate chromatin quantitatively, the extract was titrated to determine the amount required to pull down all of the DNA and histone H3. For each titration, the amount of histone $\mathrm{H} 3$, histone $\mathrm{H} 2 \mathrm{~B}$ and DNA was analyzed in the supernatant and histone $\mathrm{H} 3$ immunoprecipitation. In order to accurately monitor histone $\mathrm{H} 2 \mathrm{~B}$, histone $\mathrm{H} 3$ and DNA, each titration was performed in duplicate. Varying amounts of extract was added to the ice-cold ChIP lysis buffer and brought to a final volume of $200 \mu$ l. The histone H3 immunoprecipitation was performed as described except that prior to washing the beads, the supernatant was retained and precipitated with two volumes of ice-cold $20 \%$ trichloroacetic acid (TCA). Following a 30 minute incubation on ice, the supernatant sample was centrifuged at $20,000 \times \mathrm{g}$ for 15 minutes at $4^{\circ} \mathrm{C}$. The pellet was washed with ice-cold acetone and resuspended in 50 $\mu 12 X$ Laemmli loading buffer. The input, supernatant and histone $\mathrm{H} 3$ immunoprecipitates were boiled for at least 30 minutes to reverse the formaldehyde crosslinks. To determine the amount of extract required to precipitate chromatin quantitatively, histone $\mathrm{H} 3$ and histone $\mathrm{H} 2 \mathrm{~B}$ in the supernatant and pull down fractions were detected by immunoblot.

In parallel, the amount of co-precipitating DNA was monitored in both the supernatant as well as histone H3 immunoprecipitates. To analyze the co-precipitating DNA present in the histone $\mathrm{H} 3$ immunoprecipitations, instead of resuspending the beads in $2 X$ Laemmli loading buffer, the beads were resuspended in $100 \mu \mathrm{l} 50$ $\mathrm{mM}$ Tris-Cl $\mathrm{pH}$ 8.0, $10 \mathrm{mM}$ EDTA and 1\% SDS. To reverse the crosslinks, the supernatant and histone $\mathrm{H} 3$ immunoprecipitations were incubated at $65^{\circ} \mathrm{C}$ overnight. In the morning $100 \mu \mathrm{g}$ proteinase $\mathrm{K}$ was added and samples were incubated at $37^{\circ} \mathrm{C}$ for 2 hours. To further purify the sample, two phenol:chloroform:isoamyl alcohol (25:24:1) extractions were performed and the nucleic acid was precipitated on dry ice after adding $10 \%$ (w/v) 3M sodium acetate, $10 \mu \mathrm{g}$ glycogen (Sigma), and 2 volumes of $95 \%$ ethanol. The nucleic acid pellet was resuspended in $20 \mu \mathrm{l} 1 \mathrm{X}$ TE and the sample was treated at $37^{\circ} \mathrm{C}$ for 1 hour with $20 \mu \mathrm{g}$ RNase A to degrade any RNA (Sigma). The entire sample was fractionated on a 
$1 \%$ agarose gel. DNA was visualized by ethidium bromide staining and quantified using a Fujifilm FLA5000.

\section{Enzymatic treatment of crosslinked material}

Cells were crosslinked with formaldehyde and WCE was prepared as described previously. To $100 \mu$ l extract, $\mathrm{CaCl}_{2}$ and $\mathrm{MgCl}_{2}$ were added to a final concentration of $10 \mathrm{mM}$. To degrade the DNA, $300 \mathrm{U}$ DNase I and $300 \mathrm{U}$ MNase were added and the samples were incubated at room temperature (RT) or $37^{\circ} \mathrm{C}$ for 30 minutes. The nucleic acid was purified with two phenol:chloroform:isoamyl alcohol (25:24:1) extractions and one chloroform extraction. Samples were incubated on dry ice for 1 hour with $10 \%(\mathrm{w} / \mathrm{v})$ of $3 \mathrm{M}$ sodium acetate, $10 \mu \mathrm{g}$ glycogen (Sigma), and 2 volumes of $95 \%$ ethanol and centrifuged at $4^{\circ} \mathrm{C}$ for 15 minutes at $15,000 \mathrm{x}$ g. The nucleic acid pellet was resuspended in $20 \mu \mathrm{l} 1 \mathrm{X}$ TE. The sample was treated at $37^{\circ} \mathrm{C}$ for 1 hour with $20 \mu \mathrm{g}$ RNase A to degrade any RNA (Sigma). Following the incubation, the sample was fractionated on a $1 \%$ agarose gel and DNA was detected using ethidium bromide staining.

\section{RESULTS AND DISCUSSION}

\section{Increasing the time of formaldehyde crosslinking does not alter the amount of Mcm10 associated with chromatin}

A key step for the successful application of the HAA is to crosslink the protein of interest efficiently to DNA/nucleosomes (directly or indirectly via protein:protein crosslinks). Variability in the formaldehyde crosslinking has been shown to affect the efficiency of the chromatin immunoprecipitation reaction (22). It has been reported previously that increasing the time of crosslinking could increase crosslinking efficiency (23). However, extended crosslinking could also result in reducing the amount of protein that is immunoprecipitated due to blocking the antibody's accessibility to the histone $\mathrm{H} 3$ epitope. In order to address how the duration of formaldehyde crosslinking affects the histone $\mathrm{H} 3$ immunoprecipitation, we compared the amount of histone $\mathrm{H} 2 \mathrm{~B}$ in the chromatin immunoprecipitation after 15 minutes or 24 hours of formaldehyde treatment. We also examined the chromatin association of Mcm10, a DNA replication factor shown to be chromatin associated in G1 and S phase of the cell cycle (21). We hypothesized that if the crosslinking efficiency of Mcm10 increased with the time of exposure to formaldehyde, then we would detect more Mcm10 after 24 hours of crosslinking. However, equivalent amounts of both $\mathrm{Mcm} 10$ and histone H2B immunoprecipitated regardless of whether the samples had been treated with formaldehyde for 15 minutes or 24 hours (Fig. 2). This indicated to us that 1) the epitope accessibility for the histone $\mathrm{H} 3$ antibody was unaffected by extensive crosslinking and 2) Mcm10 was crosslinked efficiently after 15 minutes.

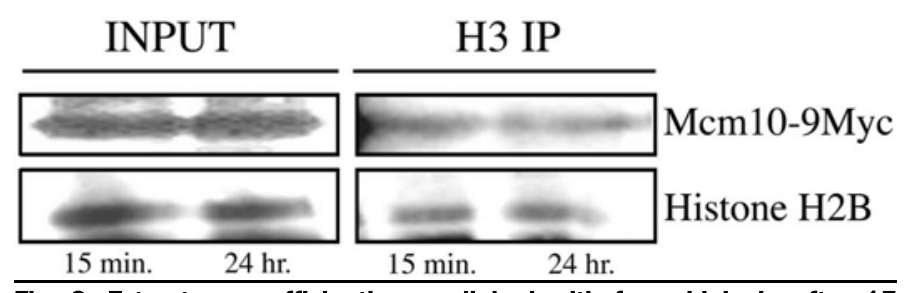

Fig. 2: Extracts are efficiently crosslinked with formaldehyde after 15 minutes of treatment. ABy025 cells (MCM10-9MYC) were arrested in G1 phase of the cell cycle by the addition of alpha factor. Mcm10-9Myc and histone H2B were detected by Western blotting in extracts quenched with glycine after 15 minutes or 24 hours of formaldehyde crosslinking. Crosslinks in WCEs (Input) and histone H3-immunoprecipitates (H3 IP) were reversed prior to SDS-PAGE. Myc (Labvision Neomarkers) and histone H2B (Upstate) specific antibodies were used for immunoblotting, respectively. Half of the input controls and all of the histone H3 immunoprecipitates were loaded.

Efficiently crosslinked chromatin is not a suitable substrate for DNase I or MNase

In an effort to determine whether the interaction between Mcm10 (a chromatin associated protein) and histone H3 was direct or mediated through DNA, the crosslinked material was treated with DNase I and MNase. Previous groups have reported fragmenting formaldehyde crosslinked chromatin with MNase or restriction enzymes as an alternative to sonication $(24,25)$. We assumed that if Mcm10 interacts with DNA but not histone $\mathrm{H} 3$ that it would no longer co-precipitate in the absence of DNA. For this experiment, samples were crosslinked with formaldehyde and sonicated to solubilize chromatin. The extract was then treated with $300 \mathrm{U}$ DNase I and $300 \mathrm{U}$ MNase for 30 minutes $\left(\mathrm{CaCl}_{2}\right.$ and $\mathrm{MgCl}_{2}$ were added since $\mathrm{Ca}^{2+}$ and $\mathrm{Mg}^{2+}$ cations are required for MNase and DNase I activity, respectively). Following the enzymatic digestion, the DNA was purified. However, we were unable to enzymatically degrade formaldehyde crosslinked DNA (Fig. 3), although we varied both the incubation times (5 - 30 
minutes) and temperatures $\left(4^{\circ} \mathrm{C}, \mathrm{RT}, 30^{\circ} \mathrm{C}, 37^{\circ} \mathrm{C}\right.$ ) (data not shown). It is possible that our inability to enzymatically digest formaldehyde crosslinked material stems from the overall amount of crosslinking under our conditions. Ladenburger et al. reported digesting formaldehyde crosslinked material from mammalian cells with MNase after only four minutes of crosslinking (25). Consistent with this, other studies reported that restriction enzyme digestion on formaldehyde crosslinked material was possible only after degrading most of the DNA bound proteins by pronase $(1,13)$. In addition, in the budding yeast, digestion of formaldehyde crosslinked material with the restriction enzyme, EcoRI, was possible if intact nuclei, but not whole cells, were treated with $1 \%$ formaldehyde for only 10 minutes (24). Taken together, our results and evidence by others document that after efficient crosslinking, DNase I and MNase are unable to enzymatically digest DNA. Thus, we were unable to distinguish whether Mcm10 was bound to DNA or to histone H3 using this approach.

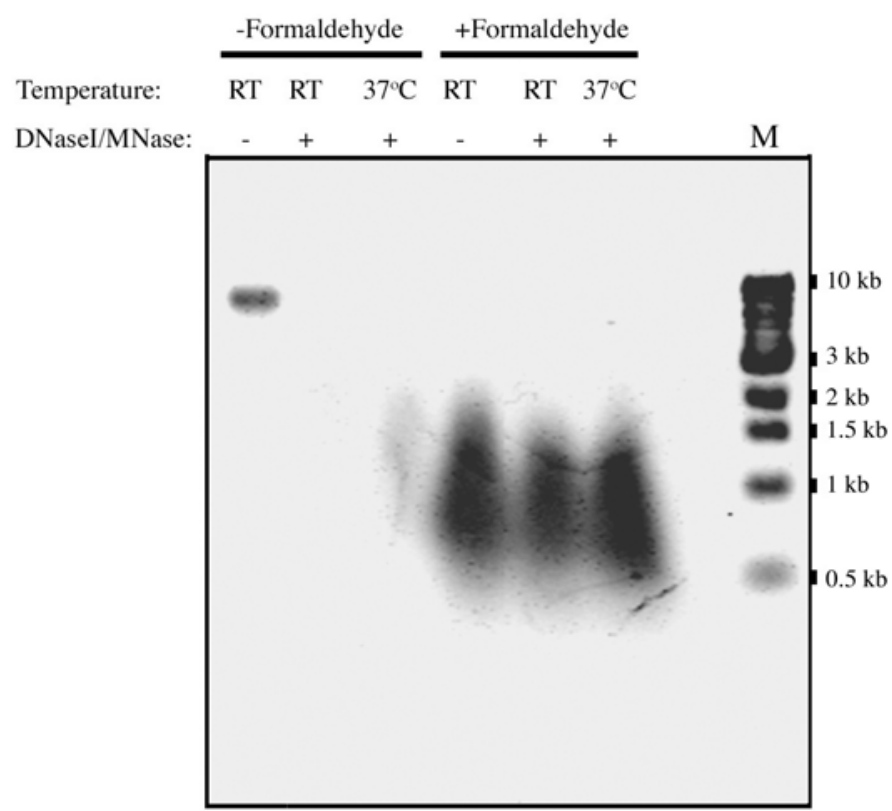

Fig. 3: Efficiently crosslinked chromatin is not a suitable substrate for DNase I or MNase. ABy025 cells (MCM10-9MYC) were either crosslinked with formaldehyde $(+)$ and quenched with glycine after 15 minutes or were left untreated (-). Formaldehyde crosslinked samples were sonicated to solubilize chromatin, while untreated samples were not. The extracts were treated with $300 \mathrm{U}$ DNase I and $300 \mathrm{U}$ MNase I for 30 minutes at either room temperature (RT) or $37^{\circ} \mathrm{C}$. DNA was purified and visualized by ethidium bromide staining.

To determine if histone $\mathrm{H} 3$ and $\mathrm{Mcm} 10$ interacted directly, we performed co-immunoprecipitation experiments in WCEs (21). We found that in samples that were not crosslinked, Mcm10 and histone H3 did not coprecipitate (21). Therefore, we concluded that the interaction between histone $\mathrm{H} 3$ and $\mathrm{Mcm} 10$ on crosslinked chromatin is likely mediated by DNA, consistent with Mcm10's ability to bind DNA in vitro (26).

\section{The relative amount of chromatin associated protein can be determined under quantitative conditions}

Mcm10 is an abundant nuclear protein and we were interested in assessing more quantitatively how much of it is bound to chromatin in cells. As shown in Figure 2, under qualitative conditions, the amount of Mcm10 in the histone $\mathrm{H} 3$ immunoprecipitations was less than in the input controls (21). In order to determine the amount that was chromatin bound, we adjusted the conditions of the HAA such that all of the bulk chromatin (measured as histone $\mathrm{H} 2 \mathrm{~B}$, histone $\mathrm{H} 3$ and DNA) in the extract was present in the immunoprecipitation (Fig. 4A). For the experiment shown in Figure 4B, we utilized $50 \mu \mathrm{l}$ (approximately $500 \mu \mathrm{g}$ ) of crosslinked WCE (21). However, the optimal amount of WCE may vary depending on the model system and antibody used for the histone immunoprecipitation. As a control, we monitored the binding of another factor, Orc2 (a subunit of the origin recognition complex) known to be a constitutive component of chromatin and found it was also precipitated quantitatively. A previous report hypothesized that all of the cellular ORC was bound to DNA in S. cerevisiae (27). Our results confirm this hypothesis, as we were able to precipitate Orc2 quantitatively [Fig. 4B and (21)]. In contrast, only 5\% of the cellular Mcm10 pool was found to be associated with chromatin in an asynchronous cell culture [Fig. 4B and (21)]. Thus, only a small fraction of Mcm10 is chromatin bound in cells. Importantly, we do not believe that these results are due to inefficient crosslinking of Mcm10 (see results shown in Fig. 2), but rather reflect the in vivo situation. For further discussion on the role of Mcm10 and the biological significance of these results, we refer the reader to our previous study (21). 
A

Titrate whole cell extract
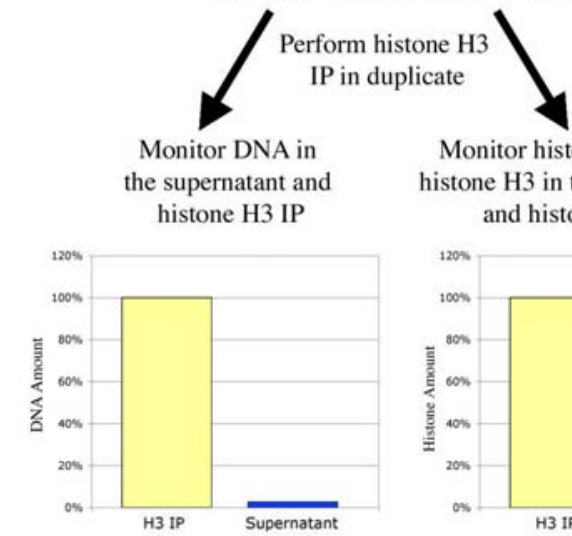
histone $\mathrm{H} 3$ in the supernatant and histone $\mathrm{H} 3 \mathrm{IP}$

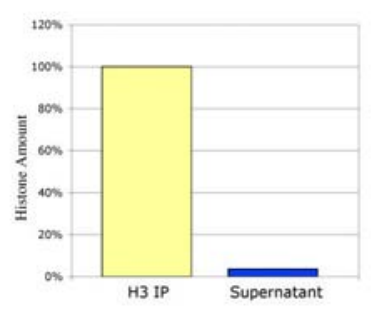

B

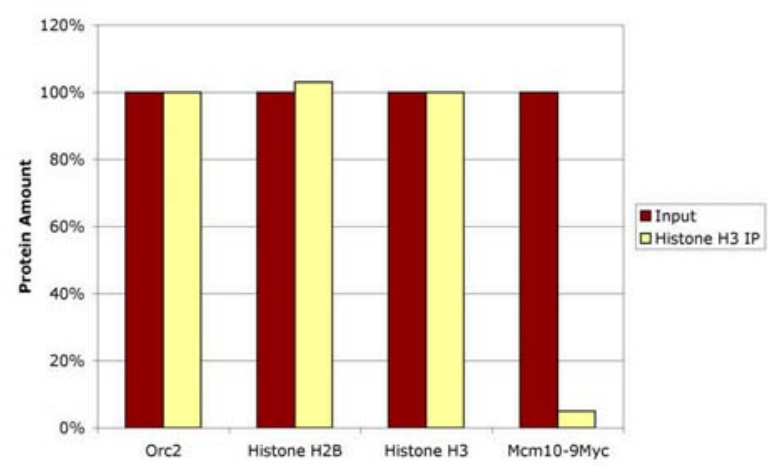

Fig. 4: Using the histone association assay under quantitative conditions. A) Flowchart for the quantitative assessment of DNA bound protein(s). Crosslinked WCEs are titrated and immunoprecipitated with histone H3specific antibodies. Both the supernatant (blue) and histone H3 immunoprecipitate (IP) (yellow) are monitored for DNA as well as histones H2B and H3. B) Bar graph representing the amounts of Orc2, histone H2B, histone $\mathrm{H3}$ and $\mathrm{Mcm} 10$ in the input (maroon) and histone H3 immunoprecipitate (IP) (yellow) under quantitative conditions, as described (21).

\section{Future applications}

The HAA is an adaptation of the ChIP protocol, and like ChIP, faces similar challenges. The factors that can complicate ChIP analysis are formaldehyde fixation, epitope accessibility and antibody specificity (28). While formaldehyde is the most commonly used chemical crosslink because of its high efficiency and ease of use, formaldehyde fixation still does have some potential pitfalls to consider. For example, covalent histone modifications may interfere with the efficiency of the formaldehyde crosslink, particularly given that formaldehyde forms crosslinks with the epsilion amino group of lysines (22), which in core histones are subject to acetylation and methylation $(29,30)$. Furthermore, the availability of the histone epitope may be an issue in regions where the density of nucleosomes is not homogeneous. In fact, Nagy et al. have shown in the budding yeast that the occupancy of nucleosomes may not be uniform (31). Other evidence suggests that some active regulatory regions are even nucleosome free (32). The ability to detect proteins bound to regions that are not as nucleosome dense through histone H3 immunoprecipitation may depend on the size of the nucleosome-low region, the size of the fragments following sonication and the nucleosomal density in neighboring regions. Nevertheless, the high abundance and the large portion of the genome occupied by histones renders them an excellent target for this assay.

Furthermore, the HAA has the potential for modification. For example, this assay could be adapted to monitor the association of certain proteins with differently modified core histones. Histone modifications have been hypothesized to mark chromatin as active or inactive for gene transcription by affecting chromatin accessibility, as described by the "histone code hypothesis" (29, 30). Comparing the chromatin association of a specific protein with differently modified chromatin regions could be accomplished by using antibodies that preferentially recognize modified epitopes on core histones for the initial immunoprecipitation step (Fig. 1). Determining the pattern of a particular protein's binding to modified histones would aid in the understanding of chromatin dynamics. In fact, several groups have examined the global distribution of modified histones on a genome wide scale using ChIP followed by hybridizing the coprecipitating DNA to genomic microarrays $(33,34)$. In the budding yeast, methylation and acetylation patterns have been mapped on a genome wide scale using antibodies that exclusively recognize those motifs (3537). In addition, acetylation and methylation patterns have also been investigated in different cell types under varying conditions in human cells (38-40) as well as in Drosophila (41). We imagine that application of the HAA in combination with proteomics might provide a powerful technique for the systematic identification of proteins that bind to modified polynucleosomes in vivo.

In conclusion, the HAA provides an easy and reliable tool to analyze protein binding to DNA in a more quantitative manner. This is especially useful for the analysis of cell cycle or developmentally regulated 
protein factors. Besides Mcm10, we have studied a variety of replication factors using the HAA. These factors include the yeast proteins Cdc45 $(74 \mathrm{kDa})$, the catalytic subunit of DNA polymerase alpha $(166 \mathrm{kDa})$, the regulatory subunit of DNA primase $(62 \mathrm{kDa})$, and Orc2 (71 kDa) (21). In principle, as long as high affinity antibodies suitable for immunoprecipitation of histones and specific antibodies recognizing the protein of interest are available, the HAA should allow for the analysis of any DNA-binding protein in eukaryotic cells.

\section{ACKNOWLEDGMENTS}

This work was supported in part by a Special Fellowship of the Leukemia and Lymphoma Society to A.-K. B. and a grant (RSG0216601) from the American Cancer Society. Special thanks go to E. A. Hendrickson for proof-reading the manuscript. The authors have no conflicts of interest to declare related to this publication.

\section{REFERENCES}

1. Solomon MJ, Larsen PL, Varshavsky A. Mapping protein-DNA interactions in vivo with formaldehyde: evidence that histone $\mathrm{H} 4$ is retained on a highly transcribed gene. Cell 1988; 53:937-947.

2. Hecht A, Strahl-Bolsinger S, Grunstein M. Spreading of transcriptional repressor SIR3 from telomeric heterochromatin. Nature 1996; 383:92-96.

3. Strahl-Bolsinger S, Hecht A, Luo K, Grunstein M. SIR2 and SIR4 interactions differ in core and extended telomeric heterochromatin in yeast. Genes Dev 1997; 11:83-93.

4. Weinmann AS, Bartley SM, Zhang T, Zhang MQ, Farnham PJ. Use of chromatin immunoprecipitation to clone novel E2F target promoters. Mol Cell Biol 2001; 21:6820-6832.

5. Weinmann AS. Novel ChIP-based strategies to uncover transcription factor target genes in the immune system. Nat Rev Immunol 2004; 4:381-386.

6. Ren B, Robert F, Wyrick JJ, Aparicio O, Jennings EG, Simon I, Zeitlinger J, Schreiber J, Hannett N, Kanin E et al. Genome-wide location and function of DNA binding proteins. Science 2000; 290:2306-2309.

7. Wyrick JJ, Aparicio JG, Chen T, Barnett JD, Jennings EG, Young RA, Bell SP, Aparicio OM. Genome-wide distribution of ORC and MCM proteins in $S$. cerevisiae: high-resolution mapping of replication origins. Science 2001; 294:2357-2360.

8. Nau GJ, Richmond JF, Schlesinger A, Jennings EG, Lander ES, Young RA. Human macrophage activation programs induced by bacterial pathogens. Proc Natl Acad Sci USA 2002; 99:1503-1508.

9. MacAlpine DM, Rodriguez HK, Bell SP. Coordination of replication and transcription along a Drosophila chromosome. Genes Dev 2004; 18:30943105.

10. Buck MJ, Lieb JD. ChIP-chip: considerations for the design, analysis, and application of genome-wide chromatin immunoprecipitation experiments. Genomics 2004; 83:349-360.

11. Geisberg JV, Struhl K. Quantitative sequential chromatin immunoprecipitation, a method for analyzing co-occupancy of proteins at genomic regions in vivo. Nucleic Acids Res 2004; 32:e151.

12. Cosma MP, Tanaka T, Nasmyth K. Ordered recruitment of transcription and chromatin remodeling factors to a cell cycle- and developmentally regulated promoter. Cell 1999; 97:299-311.

13. Solomon MJ, Varshavsky A. Formaldehydemediated DNA-protein crosslinking: a probe for in vivo chromatin structures. Proc Natl Acad Sci USA 1985; 82:6470-6474.

14. Kurdistani SK, Grunstein M. In vivo protein-protein and protein-DNA crosslinking for genomewide binding microarray. Methods 2003; 31:90-95.

15. Donovan S, Harwood J, Drury LS, Diffley JF. Cdc6pdependent loading of $\mathrm{Mcm}$ proteins onto prereplicative chromatin in budding yeast. Proc Natl Acad Sci USA 1997; 94:5611-5616.

16. Young MR, Tye BK. Mcm2 and Mcm3 are constitutive nuclear proteins that exhibit distinct isoforms and bind chromatin during specific cell cycle stages of Saccharomyces cerevisiae. Mol Biol Cell 1997; 8:1587-1601.

17. Uchiyama M, Griffiths D, Arai K, Masai H. Essential role of Sna41/Cdc45 in loading of DNA polymerase alpha onto minichromosome maintenance proteins in fission yeast. J Biol Chem 2001; 276:26189-26196.

18. Uchiyama M, Wang TS. The B-subunit of DNA polymerase alpha-primase associates with the origin recognition complex for initiation of DNA replication. Mol Cell Biol 2004; 24:7419-7434. 
19. Liang C, Stillman B. Persistent initiation of DNA replication and chromatin-bound MCM proteins during the cell cycle in cdc6 mutants. Genes Dev 1997; 11:3375-3386.

20. Zou L, Stillman B. Formation of a preinitiation complex by S-phase cyclin CDK-dependent loading of Cdc45p onto chromatin. Science 1998; 280:593-596.

21. Ricke RM, Bielinsky AK. Mcm10 regulates the stability and chromatin association of DNA polymerase-alpha. Mol Cell 2004; 16:173-185.

22. Orlando V. Mapping chromosomal proteins in vivo by formaldehyde-crosslinked-chromatin immunoprecipitation. Trends Biochem Sci 2000; 25:99-104.

23. Kaufman BA, Newman SM, Hallberg RL, Slaughter CA, Perlman PS, Butow RA. In organello formaldehyde crosslinking of proteins to mtDNA: identification of bifunctional proteins. Proc Natl Acad Sci USA 2000; 97:7772-7777.

24. Dekker J, Rippe K, Dekker M, Kleckner N. Capturing chromosome conformation. Science 2002; 295:13061311.

25. Ladenburger EM, Keller C, Knippers R. Identification of a binding region for human origin recognition complex proteins 1 and 2 that coincides with an origin of DNA replication. Mol Cell Biol 2002; 22:1036-1048.

26. Fien K, Cho YS, Lee JK, Raychaudhuri S, Tappin I, Hurwitz J. Primer utilization by DNA polymerase alpha-primase is influenced by its interaction with Mcm10p. J Biol Chem 2004; 279:16144-16153.

27. Rowley A, Cocker JH, Harwood J, Diffley JF. Initiation complex assembly at budding yeast replication origins begins with the recognition of a bipartite sequence by limiting amounts of the initiator, ORC. EMBO J 1995; 14:2631-2641.

28. Hanlon SE, Lieb JD. Progress and challenges in profiling the dynamics of chromatin and transcription factor binding with DNA microarrays. Curr Opin Genet Dev 2004; 14:697-705.

29. Strahl BD, Allis CD. The language of covalent histone modifications. Nature 2000; 403:41-45.

30. Jenuwein T, Allis CD. Translating the histone code. Science 2001; 293:1074-1080.

31. Nagy PL, Cleary ML, Brown PO, Lieb JD. Genomewide demarcation of RNA polymerase II transcription units revealed by physical fractionation of chromatin. Proc Natl Acad Sci USA 2003; 100:63646369.
32. Lee CK, Shibata Y, Rao B, Strahl BD, Lieb JD. Evidence for nucleosome depletion at active regulatory regions genome-wide. Nat Genet 2004; 36:900-905.

33. Bernstein BE, Humphrey EL, Liu CL, Schreiber SL. The use of chromatin immunoprecipitation assays in genome-wide analyses of histone modifications. Methods Enzymol 2004; 376:349-360.

34. Roh TY, Ngau WC, Cui K, Landsman D, Zhao K. High-resolution genome-wide mapping of histone modifications. Nat Biotechnol 2004; 22:1013-1016.

35. Bernstein BE, Humphrey EL, Erlich RL, Schneider R, Bouman P, Liu JS, Kouzarides T, Schreiber SL. Methylation of histone H3 Lys 4 in coding regions of active genes. Proc Natl Acad Sci USA 2002; 99:86958700.

36. Robyr D, Suka Y, Xenarios I, Kurdistani SK, Wang A, Suka N, Grunstein M. Microarray deacetylation maps determine genome-wide functions for yeast histone deacetylases. Cell 2002; 109:437-446.

37. Kurdistani SK, Tavazoie S, Grunstein M. Mapping global histone acetylation patterns to gene expression. Cell 2004; 117:721-733.

38. Kondo Y, Shen L, Yan PS, Huang TH, Issa JP. Chromatin immunoprecipitation microarrays for identification of genes silenced by histone $\mathrm{H} 3$ lysine 9 methylation. Proc Natl Acad Sci USA 2004; 101:73987403.

39. Roh TY, Cuddapah S, Zhao K. Active chromatin domains are defined by acetylation islands revealed by genome-wide mapping. Genes Dev 2005; 19:542552.

40. Bernstein BE, Kamal M, Lindblad-Toh K, Bekiranov S, Bailey DK, Huebert DJ, McMahon S, Karlsson EK, Kulbokas EJ 3rd, Gingeras TR et al. Genomic maps and comparative analysis of histone modifications in human and mouse. Cell 2005; 120:169-181.

41. Schubeler D, MacAlpine DM, Scalzo D, Wirbelauer C, Kooperberg C, van Leeuwen F, Gottschling DE, O'Neill LP, Turner BM, Delrow J et al. The histone modification pattern of active genes revealed through genome-wide chromatin analysis of a higher eukaryote. Genes Dev 2004; 18:1263-1271. 


\section{PROTOCOLS}

1. To $50 \mathrm{ml}$ log-phase yeast culture, add $1.35 \mathrm{ml}$ 37\% formaldehyde. Leave at room temperature (RT) with occasional mixing for 15 minutes.

2. Add $0.47 \mathrm{~g}$ glycine to quench the crosslinking (final concentration $125 \mathrm{mM}$ ). Incubate at RT for 5 minutes with occasional mixing.

3. Spin at RT at 3,000 rpm to pellet cells. Wash two times with $50 \mathrm{ml}(20 \mathrm{mM}$ Tris-Cl pH 7.4, $150 \mathrm{mM} \mathrm{NaCl})$.

4. Resuspend cell pellet in ice-cold ChIP lysis buffer. For $50 \mathrm{ml}$ of culture, add $400 \mu \mathrm{l}$ of ChIP lysis buffer.

ChIP Lysis buffer:

- 50 mM HEPES-KOH pH 7.5

- $140 \mathrm{mM} \mathrm{NaCl}$

- 1 mM EDTA, $\mathrm{pH} 8.0$

- $1 \%$ Triton X100

- $0.1 \%$ sodium deoxycholate

- protease inhibitors (final concentrations: $1 \mathrm{mM}$ PMSF, $1 \mu \mathrm{g} / \mathrm{ml}$ pepstatin, $1 \mu \mathrm{g} / \mathrm{ml}$ leupeptin, $1 \mathrm{mg} / \mathrm{ml}$ bacitracin, $1 \mathrm{mM}$ benzamidine). For details, see manufacturers' recommendations.

5. Add acid-washed glass beads (Sigma \#G8772) to half the volume. Vortex at the highest setting for 30-40 minutes at $4^{\circ} \mathrm{C}$ (Vortex Genie).

6. Puncture the bottom of the eppendorf tube containing the sample with a hot $25 \mathrm{~g}$ needle. Place in another eppendorf tube that contains 1-2 $\mu 100 \mathrm{mM}$ PMSF. Spin tubes in the centrifuge $\left(4,000 \times \mathrm{g}, 4^{\circ} \mathrm{C}\right.$, one minute or less).

7. Place all samples on ice. Sonicate each sample three times for 10-15 seconds while on ice. Set to setting "2" (Fisher Scientific, Sonic Dismembrator, Model 100). Leave 1 minute between each sonication. The DNA should be fragmented from approximately $2 \mathrm{~kb}$ to $500 \mathrm{bp}$.

8. Spin samples at 20,000 $\mathrm{x} g$ in a refrigerated microcentrifuge for five minutes. Keep the supernatant and discard the pellet. Add 1-2 $\mu 100 \mathrm{mM}$ PMSF to the supernatant.

9. Spin the supernatant from above for 15 minutes at $20,000 \times \mathrm{g}$ in refrigerated microcentrifuge. Keep the supernatant.

10. If necessary, adjust the volume of the samples with cold ChIP lysis buffer such that all the samples are equal.

11. Remove 50 to $100 \mu \mathrm{l}$ and add 1 volume 2 X Laemmli loading buffer ( $4 \%$ SDS, $20 \%$ glycerol, $120 \mathrm{mM}$ Tris-Cl, $\mathrm{pH} 6.8$, $200 \mathrm{mM}$ DTT, bromophenol blue) for the input control.

12. Remove another $100 \mu \mathrm{l}$ (approximately $1 \mathrm{mg}$ of total protein according to Bradford assay) and add $100 \mu \mathrm{l}$ of ChIP lysis buffer and 8-10 $\mu \mathrm{l}$ of rabbit polyclonal histone $\mathrm{H3}$ antibody (Abcam \#ab1791). Incubate overnight at $4^{\circ} \mathrm{C}$ with shaking. This antibody was originally raised against human histone $\mathrm{H} 3$ and should therefore be applicable to many, if not all eukaryotic model systems. In addition, we tested a variety of histone H3-specific antibodies from different commercial sources. This antibody performed by far the best.

13. In the morning, add $20 \mu \mathrm{g}$ single-stranded herring sperm DNA (Promega).

14. Add $50 \mu \mathrm{l}$ of a $50 \%$ slurry of protein $\mathrm{G}$ beads (Amersham \#17-0618-01). Prior to adding the beads, wash them eight to ten times in 1X PBS and then once in ChIP lysis buffer.

15. Rock at $4^{\circ} \mathrm{C}$ for 90 minutes.

16. Pellet the beads by centrifuging at $5,000 \mathrm{rpm}$ for 1 minute.

17. Wash the beads:

- Wash twice for 5 minutes at RT with $1 \mathrm{ml}$ lysis buffer

- Wash once for 5 minutes at RT with $1 \mathrm{ml}$ lysis buffer containing $500 \mathrm{mM} \mathrm{NaCl}$

- Wash once for 5 minutes at RT with $1 \mathrm{ml}$ ChIP washing buffer (10 mM Tris-Cl pH 8.0, 0.25 M LiCl, 0.5\% NP40, $0.5 \%$ sodium deoxycholate) 
- Wash once for 5 minutes with $1 \mathrm{ml}$ of ChIP lysis buffer.

18. Spin beads for 2 minutes at 5,000 rpm. Carefully remove supernatant and add $50 \mu 12 X$ Laemmli loading buffer to the beads.

19. Reverse crosslinks by boiling at least 30 minutes. Cool on ice. Spin beads down by centrifuging 5,000 rpm for 1 minute. Insufficient crosslink reversal may cause multiple higher molecular weight bands in addition to the specific signal. This can be a problem when the samples are boiled for less than 30 minutes.

20. Perform SDS-PAGE and Western blotting for the desired protein. As a control, we assay for histone H2B (Upstate \#07-371).

21. For signal quantification, we utilize a FujiFilm FLA5000 PhosphoImager and measure band intensity of multiple exposures using the computer program ImageGauge. The amount of bound protein is expressed as the ratio of pull down to input (PD/input). 